\title{
Production Potential and Development of a Decision Support Models for the Plantations of Aleppo Pine in the Oued Laou Watershed in the Moroccan Rif
}

\author{
Tayeb El Maadidi 1,* (D), Ahmed El Aboudi ${ }^{2}$ (D), Youssef Dallahi ${ }^{3}$, Hlal El Aid ${ }^{4}$
}

1 Research Centre Biotechnology Vegetal and Microbial, Biodiversity and Environment, Faculty of Science, Mohammed V University in Rabat, Morocco; tayebmaadidi@gmail.com (T.M.);

2 Botany Team and Valorisation of Plant and Fungal Resources (BOVAREF), Research Centre Biotechnology Vegetal and Microbial, Biodiversity and Environment, Faculty of Science, Mohammed V University in Rabat, Morocco; elaboudi@gmail.com (A.A.);

3 Cadi Ayyad University, Laboratoire of Microbial Biotechnologies, Agrosciences and Environment, Team of Agrosciences and Environment, Faculty of Sciences Semlalia, Marrakech, Morocco; dallahi.youssef1@ gmail.com (Y.D.);

4 National School of Forestry Engineering, Department of Management and Economy of Natural Resources, Sale Morocco, janathlal.a@menara.ma (H.E.);

* Correspondence: tayebmaadidi@gmail.com (T.M.);

Received: 8.04.2021; Revised: 8.06.2021; Accepted: 10.06.2021; Published: 7.09.2021

Abstract: The present study was carried out in the Oued Laou watershed belonging to the Moroccan Rif. It aims at the elaboration of mathematical tariffs for cubing Aleppo pine, the morphometric and increments study. The data analyzed for this purpose were collected after a preliminary stratification of the forest based on the plantation age. The study of the region's climate shows that the western sector of the watershed is part of the temperate humid bioclimate, and the eastern sector belongs to the warm variant subhumid. The analysis of the stand-study structure shows that the distribution of the number of stems as a function of the circumference is a distribution close to normal. Cubic rates have been constructed to estimate the volume of trees. The mean annual volume increment of Aleppo pine varies between 3.10 and $4.83 \mathrm{~m}^{3} / \mathrm{ha} / \mathrm{year}$ from one plot to another; this small fluctuation largely reflects the homogeneity of the study area. Aleppo pine has a wide ecological and spatial plasticity: colonization of all substrates, bioclimates ranging from semi-arid to temperate humid. It's a species that exhibits uniform behavior despite topographic and edaphic variations.

Keywords: bioclimate; cubic rate; mean annual volume increment; structure.

(C) 2021 by the authors. This article is an open-access article distributed under the terms and conditions of the Creative Commons Attribution (CC BY) license (https://creativecommons.org/licenses/by/4.0/).

\section{Introduction}

Morocco has a privileged geographical location between the Mediterranean sea in the North, the Atlantic sea in the West, and the Sahara in the south. Morocco also has a variety of natural environments with a great floristic and faunistic diversity (biodiversity). The National Forest area is about 9 Million hectares, corresponding to an afforestation rate of $8 \%$ [1].

Aleppo pine (Pinus halepensis Mill.), widespread in North Africa, is a spontaneous species in Morocco, where it occupies a relatively small area of about 65,325 ha [2]. It is distributed in larger or smaller areas, stretching from the Mediterranean coast to the High Atlas Mountains. Rarely found in its pure state, Aleppo pine often comes into contact with Berberian 
thuja, red juniper, holm oak, cork oak, or kermes oak, with which it forms pre-forest or presteppe stands[3].

Owing to its great plasticity, indifference to the soil structure, and hardiness, Aleppo pine is among the first species used for reforestation in Morocco [4]. Moreover, it was selected as one of the species in the regular reforestation plan established by the National Reforestation Plan. Thus, Aleppo pine has been widely used for protective, productive, and recreational reforestation. Table 1 shows the surface area of pines used in reforestation in Morocco with the predominance of the Aleppo pine area, which represents $76 \%$.

Table 1. Pine areas used in reforestation in Morocco [3].

\begin{tabular}{l|c|c}
\multirow{2}{*}{ Species } & \multicolumn{2}{|c}{ Area } \\
\cline { 2 - 3 } & Ha & \% \\
\hline Aleppo pine & 252,743 & 76 \\
\hline $\begin{array}{l}\text { Other pine species (maritime pine, Canary pine, } \\
\text { Monterey pine, stone pine ...) }\end{array}$ & 125,690 & 34 \\
\hline Total & 378,433 & 100
\end{tabular}

However, previous research dealing with Moroccan Aleppo pine productivity and growth remains spatially dislocated, not covering all the ecological conditions in which this species develops.

This lack of information constitutes a handicap for Aleppo pine forest management. Therefore, we found it useful to conduct the present study of Aleppo pine potential production in the Oued Laou watershed in the North of Morocco (Rif) sets.

This study aims to develop and test single-entry cubing rates, two-entry cubing rates, stand volume tariffs, and the increments study and compare these tariffs with others established for the same species in Morocco.

\section{Materials and Methods}

\subsection{Study area and data.}

The study area belongs to the Oued Laou watershed (Fig. 1). It is part of the province of Tetouan, the district of Tetouan and the communes of Hamra, Beni Lait and El Oued. It is located in the Western Rif and is drained by the Oued Moulay Bouchta.

The watershed's forests are managed by the forest service of Tetouan and the Ben Karrich forestry sector.

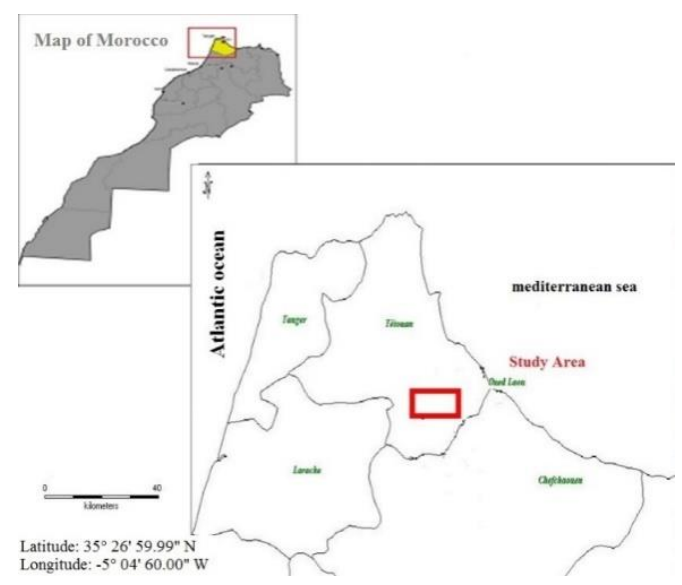

Figure 1. Geographical site of the study area. 
The average annual precipitation varies between $604 \mathrm{~mm}$ and $1777 \mathrm{~mm}$. The temperature is relatively moderate; the monthly average ranges from 12.7 to $24.9{ }^{\circ} \mathrm{C}$. The climate is of the Mediterranean type and has been dry. The dry period lasts 5 months. The seasonal regime of the watershed is Winter-spring-autumn summer type. The bioclimate is of sub-humid type; its temperature varies from hot to humid to temperate.

The surveys sampled at the Aleppo pine reforestation sites are located on moderately deep soils in all the exposed areas. Two types of substrates were described, namely sandstone and limestone. Bioclimatic conditions are favorable. The floristic procession is constituted by the following species: Cistus monspeliensis L.; Cistus monspeliensis L.; Daphne gnidium L.;Smilax aspera L.; Nerium oleander L.; Arbutus unedo L.;Phillyrea latifolia L.; Myrtus communis L.; Rubus ulmifolius Schott.

The land-uses in the study area are as follows: natural cork-oak forest, reforestation based on Aleppo pine which covers an area of 104 ha, maritime pine and radiata pine, matorral, cereal-based agriculture, and arboriculture.

\subsection{Methodology.}

\subsubsection{Sampling.}

The plantation of the Aleppo pine belonging to the watershed covers an area of 104 ha and contains plantations of the same age. Systematic sampling, therefore, seems to be an effective way to study this environment.

\subsubsection{Sample size.}

A scheme of 32 plots was adopted to cover the perimeter, i.e., a sampling rate of approximately one plot per hectare. Circular plots of 3 acres were created. This dimension was chosen during a preliminary inventory; it includes an average of 15 trees.

\subsubsection{Distribution of plots in the field.}

We applied a systematic distribution of survey plots using a square grid.

\subsubsection{Information to collect.}

To meet the objectives of this study, two types of information were collected at each plot level:

- phyto-ecological descriptors (altitude, slope, topography, exposure) that describe the station;

- the dendrometric parameters related to the tree (the circumference at $1.30 \mathrm{~m}$ from the tree, the circumference of the stumps, the total height of the dominant trees).

2.2.2.Presentation and choice of models.

The overall tree volume is a necessary quantity for estimating the carbon stored by trees. Within the framework of this research, we have adjusted the functions most often used in the forestry literature [10]. 


\subsubsection{Single-entry cubing rates.}

Single-entry cubage tariffs explain the volume in terms of the circumference up to $1.30 \mathrm{~m}$ from the ground. They are less accurate than two-entry tariffs. The rationale for their use is the simplicity and timeliness of the estimates. These tariffs, intended for homogeneous stand volume, are often used in forest management for future recruitment. The formulas (1-3) of this model are as follows:

$$
\begin{aligned}
& V=a_{0}+a_{1} \cdot C^{2}, \\
& V=a_{0}+a_{1} \cdot C+a_{2} \cdot C^{2}, \\
& V=a \cdot C^{b},
\end{aligned}
$$

where: $V$ is the estimated volume, $\mathrm{m}^{3} / \mathrm{ha} ; a_{\mathrm{i}}$ are regression coefficients; $C$ is circumference up to $1.30 \mathrm{~m}$ from the ground, $\mathrm{m}$.

\subsubsection{Two-entry cubing rates.}

These models are more accurate than the previous one, but they require a certain amount of caution in their use, knowing that in practice heights are estimated, which can lead to inadmissible imprecision. The formulas (4-5) of this model are follows:

$$
\begin{gathered}
V=a_{0}+a_{1} \cdot C^{2} \cdot H \\
V=a_{0}+a_{1} \cdot C^{2}+a_{2} \cdot C^{2} \cdot H \\
V=a_{0}+a_{1} \cdot C+a_{2} \cdot C^{2} \cdot H \\
V=a_{0}+a_{1} \cdot C+a_{2} \cdot C^{2}+a_{3} \cdot C^{2} \cdot H \\
\quad V=a \cdot C^{\mathrm{b}} \cdot H^{\mathrm{d}}
\end{gathered}
$$

where: $V$ is volume of the tree $\mathrm{m}^{3} / \mathrm{ha}$.

$C$ is circumference at $1.30 \mathrm{~m}$ from the ground, $\mathrm{cm} ; H$ is total tree height, $\mathrm{m} ; a_{\mathrm{i}}$ are regression coefficients to be estimated $(i=0,1, \ldots)$.

\subsubsection{Stand volume tariffs.}

Stand volume tariffs have the advantage of quickly estimating growing stock by taking precise measurements of stand characteristics such as the basal area per hectare of a stand, dominant height, density per hectare, and average height per hectare. The formulas (9-13) of this model are follows:

$$
\begin{gathered}
V=b_{0}+b_{1} \cdot H \mathrm{~d} \cdot G \\
V=b_{0}+b_{1} \cdot G+b_{2} \cdot H \mathrm{~g} \\
V=b_{0}+b_{1} \cdot H \mathrm{~g}+b_{2} \cdot G^{2} \\
V=b_{0}+b_{1} \cdot C \mathrm{~g}^{2} \\
V=b_{0}+b_{1} \cdot \mathrm{Hg}
\end{gathered}
$$

where: $V$ is the volume per hectare, $\mathrm{m}^{3} / \mathrm{ha} ; b_{\mathrm{i}}$ are regression coefficients; $C \mathrm{~g}$ is the circumference of the average shaft, $\mathrm{cm} ; G$ is base area per hectare, $\mathrm{m}^{2} / \mathrm{ha} ; H \mathrm{~d}$ is dominant height, $\mathrm{m} ; \mathrm{Hg}$ is the average height of the tree, $\mathrm{m}$.

The choice of the ideal model depends on various statistical criteria that can be summarized as follows :

- the coefficient of determination $\left(\mathrm{R}^{2}\right)$ which represents the part of the variation, is explained by the model (the bigger it is, the better the model is); 
- the residual standard deviation (Sy.x) measures the dispersion of the residuals represented by the differences between observed and estimated volumes (the smaller it is, the better the model is);

- the t-test of Student's regression coefficients (these coefficients must be significantly different from zero);

- graphical examination of the residuals provides further information on the validity and quality of the model.

To compare the models that have transformed the dependent variable, Furnival [5] proposes an adjustment index based on the concept of maximum likelihood, which is always valid whatever the type of equation used. This index is calculated by the formula (14).

$$
\mathrm{IF}=\mathrm{S}_{\mathrm{y} . \mathrm{x}}\left[\mathrm{f}^{\prime}(\mathrm{v})\right]^{-1} \text {, }
$$

where: IF is index Furnival; $S_{y . x}$ is the residual standard deviation; $f^{\prime}(v)$ is first derivative of the dependent variable; [...] is geometric average. The lowest index indicate the best model.

In addition to these statistical criteria, the best model choice also depends on how easy it is for the manager to use the tariff.

\subsubsection{Validation of the model.}

To validate the model, several authors [6] propose to apply the tariff to a batch of trees that have not been used for its construction and then calculate the following two expressions:

\subsubsection{The relative average of cubing errors.}

The tariff was constructed from a sample of trees representative of the stands studied. The error made by applying it to the volume is obtained by calculating the mean of cubing errors [7]. It is given by formula (15).

$$
e_{m}=\frac{\frac{1}{n} \sum e_{i}}{V_{m}},
$$

where: $e_{i}=V_{\mathrm{i}}-V_{\mathrm{e}} ; V_{\mathrm{i}}$ is observed volume of tree, $\mathrm{m}^{3} ; V_{\mathrm{e}}$ is estimated volume of the tree by tariff, $\mathrm{m}^{3} ; V_{\mathrm{m}}$ is the average volume of tree observed, $\mathrm{m}^{3} ; n$ is several trees in the plot.

\subsubsection{The relative standard deviation of the distribution of cubing errors.}

This parameter allows quantifying the error made by applying the tariff constructed. It corresponds to the difference between the actual volume of the tree and the estimated one[8]. It is given by formula (16).

$$
S_{e}=\frac{\frac{1}{n} \sum\left(e_{i}-e_{m}\right)}{V_{m}}
$$

The lowest parameter indicates the best model.

\subsubsection{Growth patterns (dominant height growth).}

A growth model is a mathematical function used to represent the change in height as a function of time[9]. It is indeed a forecasting tool for the manager who seeks to determine the future value of the growth of trees and stands. The evolution of the dominant height using the 
age of the reforestation studied was carried out by analyzing the models represented by formulas (17-20):

- Hossfeld model: $H_{d}=\frac{A^{2}}{b_{0}+b_{1} \cdot A+b_{2} \cdot A^{2}}$,

- Farrar model:

$$
H_{d}=M \exp \left(\frac{b_{0}}{A}+\frac{b_{1}}{A^{2}}+\frac{b_{2}}{A^{3}}\right)
$$

- Schumacher model:

$$
H_{d}=M \cdot \exp \left(\frac{b}{A^{0.5}}\right)
$$

where: $H_{d}$ is dominant height, $\mathrm{m} ; A$ is age, years; $M, b_{0}, b_{1}$, and $b_{2}$ are regression parameters.

The choice of the model is based on the statistical criteria already described, namely: the coefficient of determination $\left(\mathrm{R}^{2}\right)$, the residual standard deviation (Sy.x), the coefficients of Student's t-test on regression, Furnival index (FI), and the graphical examination of the residuals.

\section{Results and Discussion}

\subsection{Stand structure.}

The structure of Aleppo pine in the study area is characterized by a unimodal distribution which describes a regular stand (Fig. 2).

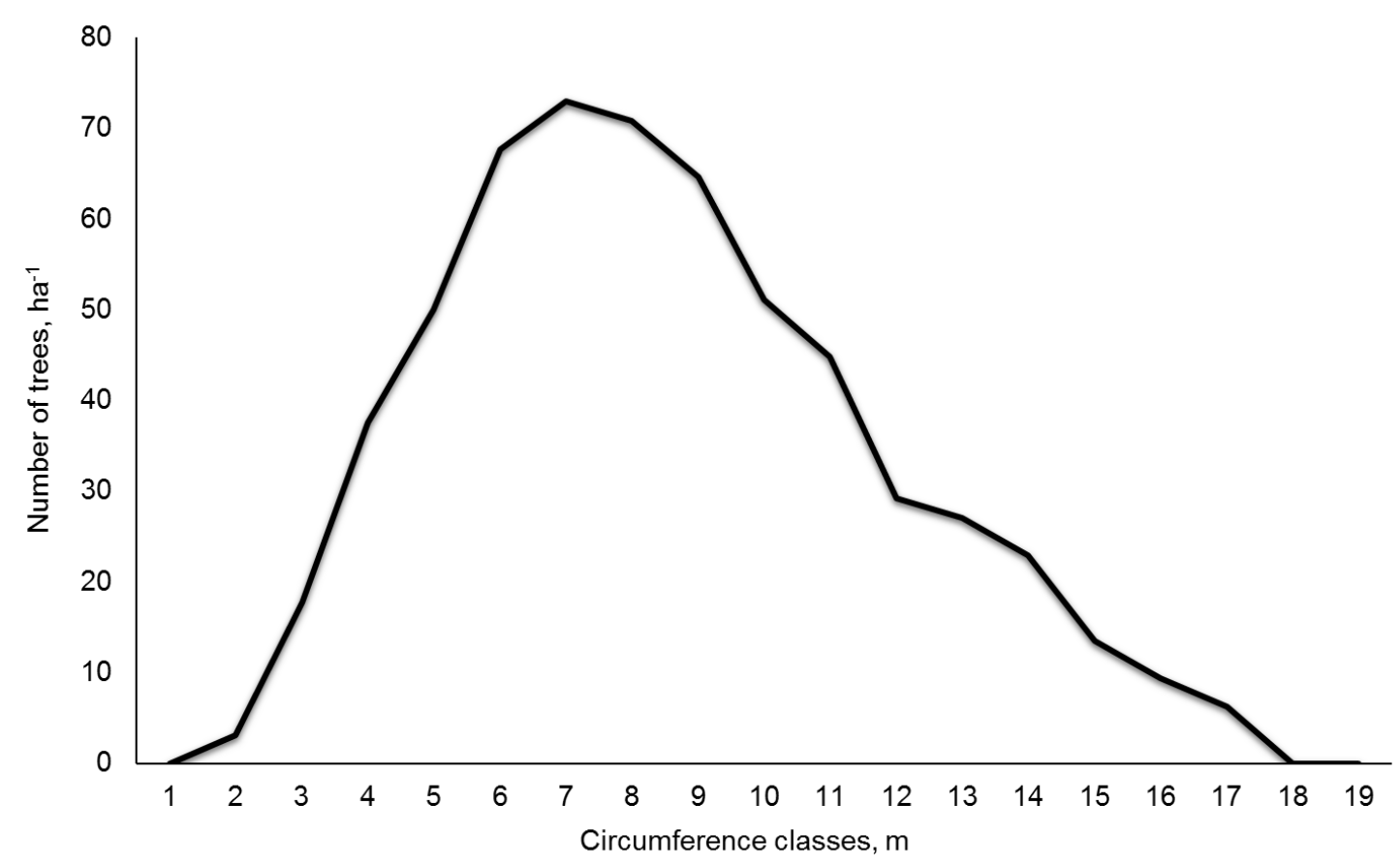

Figure 2. Distribution of Aleppo pine stems by circumference classes.

The distribution of the number of trees by circumference classes is characterized by a single-mode located in the circumference class [65-74 cm]. The histogram schematizing the distribution of the observed stems by circumference classes shows an asymmetry to the left with a coefficient of 0.22 . The shift of the distribution to the left occurred following the succession of several cuts made from a young age. 


\subsection{Adjustment of structures.}

Adjustment is an operation that consists of comparing an observed distribution with another theoretical one, which is the normal distribution. This is based on the results of adjustment tests based on Pearson's $\chi^{2}$ distributions [7,9]. The parameters of these tests are the arithmetic mean of the circumferences and the standard deviation of the circumferences. These parameters were calculated through the sampled dendrometric data.

Knowing these two parameters allows explaining the distribution function.

The results of the Parameters of trees estimated by a normal distribution are summarized in Table 2.

Table 2. Parameters of trees estimated by a normal distribution.

\begin{tabular}{l|l|l} 
Parameters & & \\
\hline Total of circumferences: & 588 & \\
\hline Arithmetic average of circumferences : & 85 & \\
\hline Standard deviation: & 32 &
\end{tabular}

The adjustment method was performed by the test $\chi^{2}$. It is given by the formula (21).

$$
\chi^{2}=\sum_{i} \frac{n_{i}^{2}}{N P_{i}}-n, i=1,2,3, \ldots \mathrm{j},
$$

where: $n=\sum n_{\mathrm{i}}$ is the total number of trees observed; $n_{\mathrm{i}}$ : is the number of trees observed for each; circumference class; $N P_{\mathrm{i}}$ is the expected (theoretical) number of trees by the normal distribution; $j$ is the number of classes observed.

The calculation of this parameter gives the following result: $\chi_{o b s}^{2}=46.47$.

According to Dagnelie [9], the expected $N P_{\mathrm{i}}$ must be at least equal to or close to 5 .

Based on the data presented, the observed $\chi^{2}$ is equal to 46.47 .

From the Pearson's chi-squared test table, the theoretical $\chi^{2}$ is equal to 24.4 (degree of freedom is 13 with a significance level of $5 \%$ ).

If we compare these two values, we conclude that the distribution of the circumference of the Aleppo pine is not normal.

The normal curve that was adjusted to the histogram of the observed distribution is shown in Figure 3.

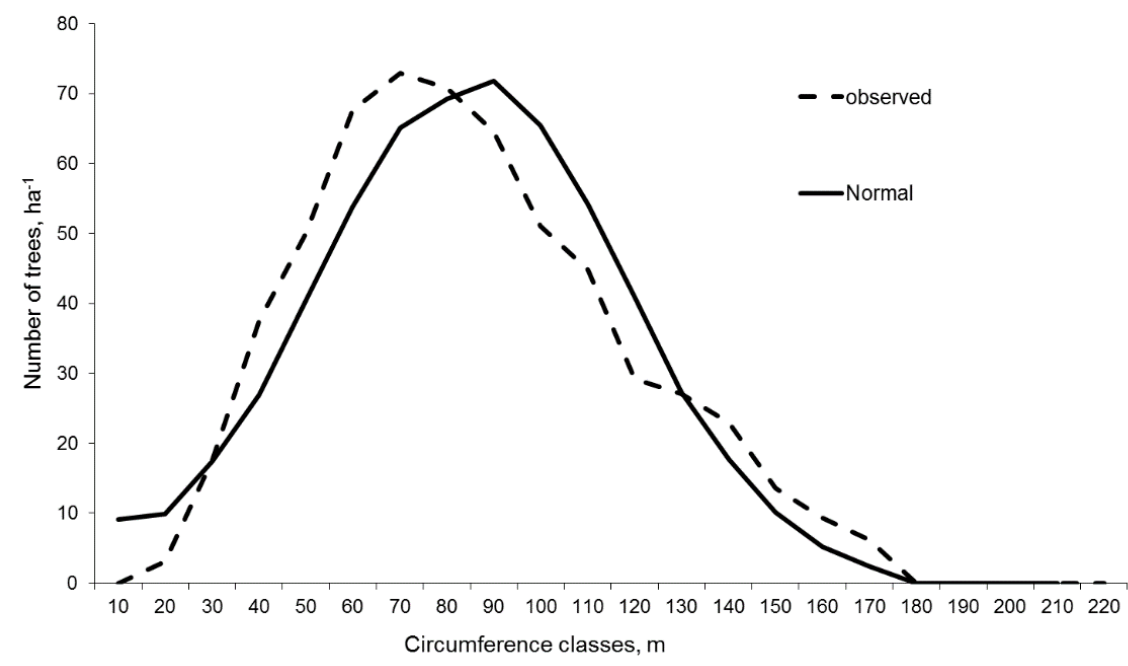

Figure 3. Adjustment of the number of stems by circumference classes to the normal distribution. 


\subsection{Wood production.}

To evaluate the wood production, cubage tariffs were constructed based on the sample trees representing the stand. Figure 4 illustrates the circumference distribution of these trees and the overall stand distribution.

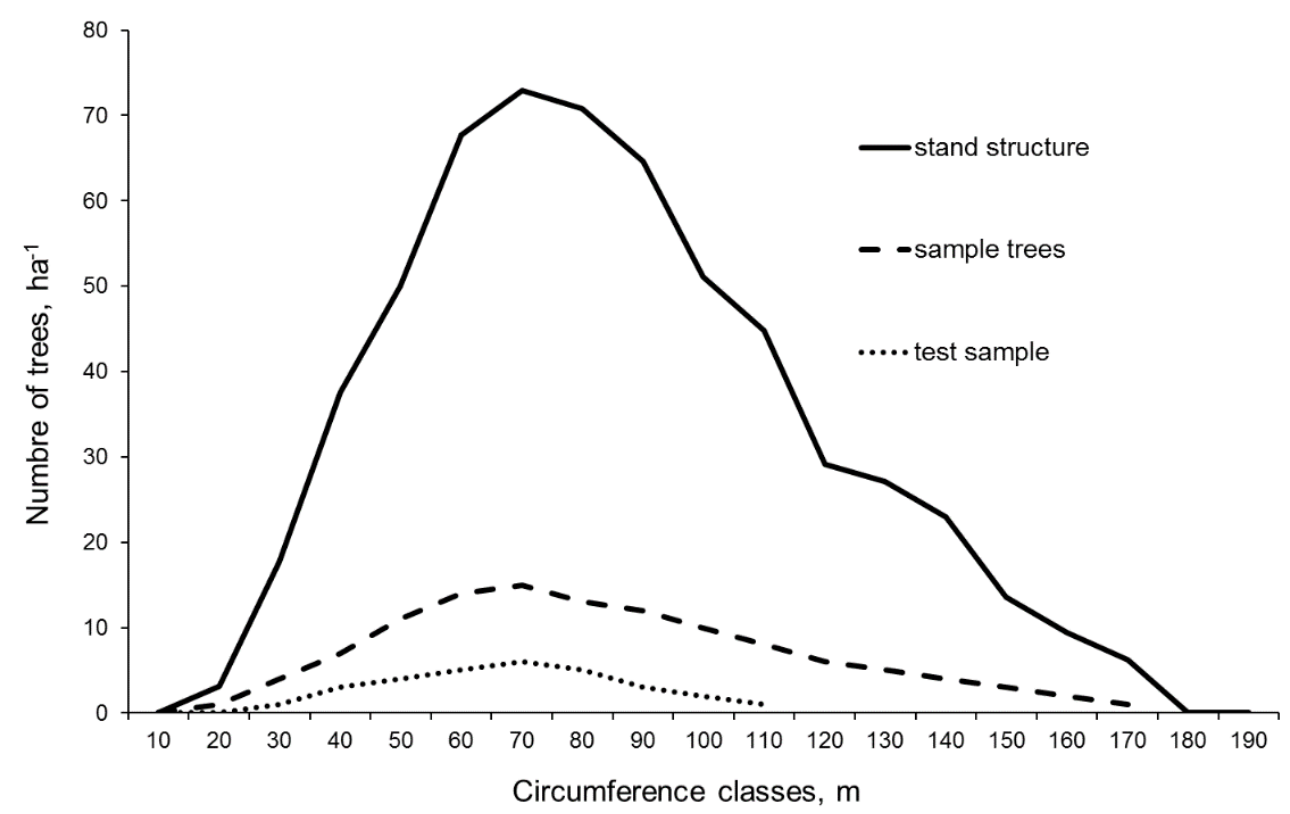

Figure 4. Structures of the stand, sample trees, and test sample.

3.3.1. Tariff for a single entry.

The adjustment results of these models and their precision criteria are mentioned in Table 3. This latter shows the adjusted models and their statistical criteria. This adjustment was performed based on 89 sample trees.

Table 3. Single-entry cubing tariffs.

\begin{tabular}{l|l|l|l|l|l} 
Mathematical models & $\mathbf{R}^{\mathbf{2}}$ & $\mathbf{S}_{\mathbf{y} . \mathbf{x}}$ & $\mathbf{I F}$ & $\boldsymbol{e}_{\boldsymbol{m}}$ & $\boldsymbol{S}_{\boldsymbol{e}}$ \\
\hline$V_{1}=-22+3.3 .10^{-2} \cdot C^{2}$ & 0.972 & 22 & 22 & -0.029 & 0.375 \\
\hline$V_{2}=34.43-1.38 \cdot C+4.10^{-2 .} C^{2}$ & 0.984 & 20 & 20 & 0.0116 & 0.048 \\
\hline$V_{3}=1.6 .10^{-2} \cdot C^{2.13}$ & 0.975 & 70.7 & 73 & 0.008 & 0.073
\end{tabular}

Note: $V$ is volume, $\mathrm{m}^{3} / \mathrm{ha} ; C$ is circumference at $1.30 \mathrm{~m}, \mathrm{~m} ; \mathrm{R}^{2}$ is the determination coefficient; $\mathrm{S}_{\mathrm{y} . \mathrm{x}}$ is residual standard deviation; $d$ is the statistic of Durbin Watson; IF is Furnival index; $e_{m}$ is the relative average of cubing errors; $S_{e}$ is the relative standard deviation of the distribution of scaling errors.

The analysis of the statistical criteria as outlined in the methodological section shows that the relationship between the variable to explain and the explanatory variable is tight. The coefficient of determination for all these models exceeds $97 \%$, and the error derived from the test trees is very slight.

Although the three models appear similar and have the same performance, their analysis gives a slight advantage to the second model, which is the easiest to use by the manager with the highest coefficient of determination. Also, the second polynomial model with a graphical distribution of residuals shows a very uniform distribution (Fig. 5).

This model is presented by formula (22).

$$
V=34.43-1.38 \cdot C^{2} \text {, }
$$

where: $V$ is volume, in $\mathrm{m}^{3} /$ ha and $C$ is circumference at $1.30 \mathrm{~m}$. 


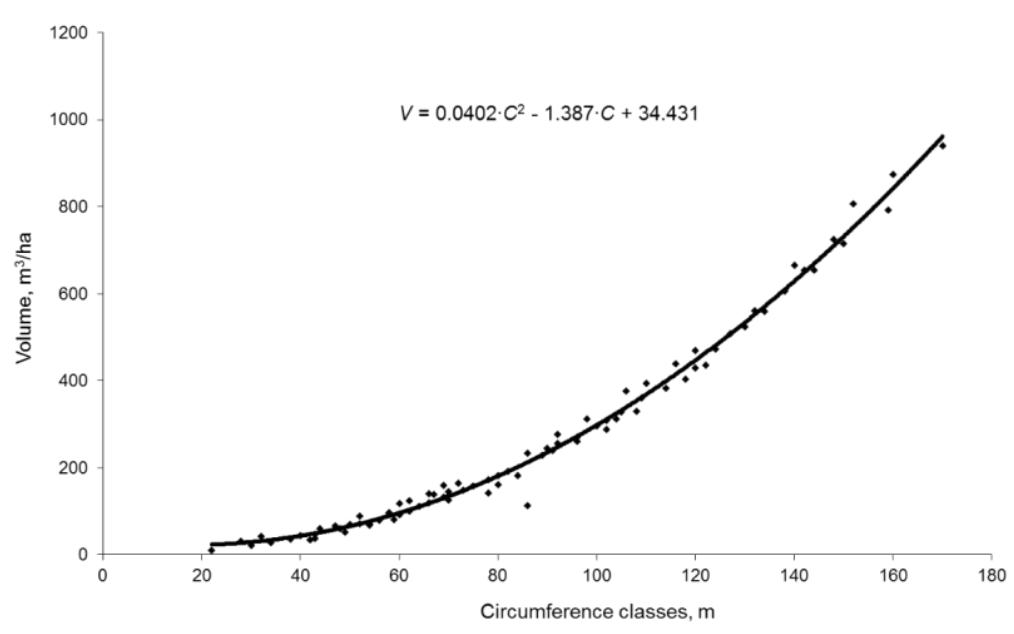

Figure 5. Volume of trees according to the circumference at $1.30 \mathrm{~m}$.

By examining this graph, the scatterplot constitutes a parabolic branch, which suggests polynomial functions. Nevertheless, this did not prevent us from also studying the allometric model.

\subsubsection{Two-entry tariff.}

The models and their precision criteria are listed in Table 4.

Table 4. Two-entry cubing tariffs.

\begin{tabular}{l|l|l|l|l|l} 
Mathematical models & $\mathbf{R}^{2}$ & $\mathbf{S}_{\mathbf{y} . \mathbf{x}}$ & $\mathbf{I F}$ & $\boldsymbol{e}_{\boldsymbol{m}}$ & $\boldsymbol{S}_{\boldsymbol{e}}$ \\
\hline$V_{1}=4+2.2 \cdot 10^{-3} \cdot C^{2} \cdot H$ & 0.991 & 18 & 18 & -0.031 & 1.45 \\
\hline$V_{2}=-2.2+7.3 \cdot 10^{-3} \cdot C^{2}+1.7 .10^{-3} \cdot C^{2} \cdot H$ & 0.993 & 18 & 18 & -0.022 & 0.9 \\
\hline$V_{3}=48-0.98 \cdot C+2.5 \cdot 10^{-3} \cdot C^{2} \cdot H$ & 0.994 & 17 & 17 & 0.004 & 1.22 \\
\hline$V_{4}=1.15 .10^{-2} \cdot C^{1.94} \cdot H^{0.46}$ & 0.997 & 130 & 134 & 0.0009 & 0.39
\end{tabular}

Note: $V$ is volume in, $\mathrm{m}^{3} / \mathrm{ha} ; C$ is the circumference at $1.30 \mathrm{~m}, \mathrm{~m} ; H$ is tree height, $\mathrm{m} ; \mathrm{R}^{2}$ is the determination coefficient; $\mathrm{S}_{\mathrm{y} . \mathrm{x}}$ is the residual standard deviation; IF is Furnival index; $e_{m}$ is the relative average of cubing errors; $S_{e}$ is the relative standard deviation of the distribution of the cubing errors.

It is worth mentioning at this point that the best model is the one that corresponds to the lowest Furnival Index (FI) also if the relative mean of the cubage errors $\left(e_{m}\right)$ and the relative standard deviation of the distribution of cubage errors $\left(S_{e}\right)$ are small, the better the adjustment by the model.

After comparing, the different models obtained (Table 4) and analyzing their residuals, the $V_{3}$ model proves to be the most adequate. This model is presented by formula (23).

$$
V=48-0.98 \cdot C+2.5 \cdot 10^{-3} \cdot C^{2} \cdot H
$$

\subsubsection{Checking tariffs.}

The cubing tariffs elaborated from the sample trees are usually marked by some errors. These errors are attributed to the batches of trees used for this purpose, the measurements of the dendrometric characteristics of these trees, and the relations between the variable to explain, which is generally the volume, and the other explanatory variables.

The cubing tariffs constructed for Aleppo pine were validated by calculating the relative average of cubing errors and their standard deviations. These parameters were determined based on a tree sample that was not used to construct the tariffs. 
For the single-entry tariff, the relative average of cubing errors is $1.16 \%$, while the two-entry tariff is $0.4 \%$. Thus, double-entry tariffs that use two independent or explanatory variables $(H$ and $C$ ) in the scaling equation are more accurate than single-entry tariffs with a single independent variable $(C)$ for the studied stand of Aleppo pine.

3.3.4. Stand volume tariffs.

The various models tested and their statistical criteria are recorded in Table 5.

Table 5. Stand volume tariffs.

\begin{tabular}{l|l|l|l|l} 
Mathematical models & $\boldsymbol{N}$ & $\mathbf{R}^{\mathbf{2}}$ & $\mathbf{S}_{\mathbf{y} . \mathbf{x}}$ & $\mathbf{F}$ \\
\hline$V_{1}=24.61 \cdot H \mathrm{~g}-127.86$ & 32 & 0.775 & 22.53 & 103.8 \\
\hline$V_{2}=0.04 \cdot G^{2}+3.30 \cdot H \mathrm{~g}+41.99$ & 32 & 0.99 & 4.79 & 2938 \\
\hline$V_{3}=3.94 \cdot G+1.81 \cdot H \mathrm{~g}-31.46$ & 32 & 0.997 & 2.52 & 10625 \\
\hline$V_{4}=0.21 \cdot H \mathrm{~d} \cdot G+40.72$ & 32 & 0.962 & 9.27 & 784
\end{tabular}

Note: $V$ is volume, $\mathrm{m}^{3} / \mathrm{ha} ; G$ basal surface, $\mathrm{m}^{2} / \mathrm{ha} ; \mathrm{R}^{2}$ is the determination coefficient; $\mathbf{S}_{\mathbf{y} . \mathbf{x}}$ is the residual standard deviation; $H \mathrm{~d}$ : dominant height, $\mathrm{m} ; \mathrm{Hg}$ is the average arithmetic height of stands, $\mathrm{m} ; \mathrm{F}$ is Fischer coefficient; $N$ is the number of trees.

Based on the analysis of Table 5, it can be observed that model $V_{3}$ has the highest coefficient of determination and the lowest residual standard deviation with the highest Fischer coefficient [10]. The regression coefficients are, therefore, significantly different from zero. For this sense, the V3 model is the most suitable for Aleppo pine stands, and it is presented by formula (24).

$$
V=-31.46+1.81 \cdot \mathrm{Hg}+3.94 \cdot G
$$

where: $V$ is volume, $\mathrm{m}^{3} / \mathrm{ha} ; G$ is surface area, $\mathrm{m}^{2} / \mathrm{ha} ; H \mathrm{~g}$ is the average arithmetic height of stands, $\mathrm{m}$.

3.3.5. Correlation between the circumference at $1.30 \mathrm{~m}\left(C_{1.30 \mathrm{~m}}\right)$ and the circumference at the stump $\left(C_{s}\right)$.

The estimation of the potential production must consider the volume of standing trees and illegal harvest [11]. Thus, relationships have been established between the circumference at $1.30 \mathrm{~m}$ and the circumference at the stump.

Given the strong correlation between these two dendrometric variables, only one linear model was tested and retained by formula (25).

$$
C_{1.30}=a_{0}+a_{1} \cdot C_{s},
$$

where: $C_{1.30}$ is circumference at $1.30 \mathrm{~m}, \mathrm{~cm} ; C_{\mathrm{s}}$ is circumference at the stump, cm; $a_{0}$ and $a_{1}$ areregression coefficients.

The results of the correlation between circumference at $1.30 \mathrm{~m}$ and stump are shown in Table 6.

Table 6. Correlation between circumference at $1.30 \mathrm{~m}$ and stump.

\begin{tabular}{l|l|l} 
Mathematical model & $\mathbf{R}^{\mathbf{2}}$ & $\mathbf{S}_{\mathbf{y} . \mathbf{x}}$ \\
\hline$C_{1.30}=-12.60+C_{\mathrm{s}}$ & 0.985 & 3.97
\end{tabular}

Note: $C_{1.30}$ is the circumference at $1.30 \mathrm{~m}, \mathrm{~cm} ; C_{\mathrm{s}}$ is the circumference at the stump, $\mathrm{cm} ; \mathrm{R}^{2}$ is the determination coefficient; $\mathrm{S}_{\mathrm{y} . \mathrm{x}}$ is the residual standard deviation.

\subsubsection{Set up of growth models.}

The evolution of the dominant height with age was established based on data gathered from 38 plots. The dominant height was determined from the average height of the three largest 
trees in each plot. The age of these plantations was determined by consulting the reforestation perimeter fascicles.

The entire data was matched to models commonly used in the forestry literature. The adjustment results are shown in Table 7 .

Table 7. Changes in the dominant height of Aleppo pine plantations by age.

\begin{tabular}{l|l|l|l|l|l} 
No & Mathematical models & $\mathbf{R}^{\mathbf{2}}$ & $\mathbf{S}_{\mathbf{y} . \mathbf{x}}$ & $\mathbf{I F}$ & $\mathbf{F}$ \\
\hline 1 & $H \mathrm{~d}=17.46 \exp \left(-14.39 / A+10.54 / A^{2}\right)$ & 0.918 & 0.20 & 0.21 & 902 \\
\hline 2 & $H \mathrm{~d}=34.12 \exp \left(-6.38 / A^{0.5}\right)$ & 0.877 & 0.30 & 0.329 & 687 \\
\hline 3 & $H \mathrm{~d}=0.44 \exp \left(0.247 \mathrm{~A}-4.4 .10^{-3} \cdot A^{2}\right)$ & 0.876 & 0.31 & 0.332 & 333 \\
\hline 4 & $H \mathrm{~d}=0.27 \cdot A^{1.12}$ & 0.903 & 0.27 & 0.292 & 539 \\
\hline 5 & $H \mathrm{~d}=A^{2} /\left(-2.2+6.14 \cdot \mathrm{A}-0.214 \cdot A^{2}\right)$ & 0.870 & 0.21 & 0.217 & 324
\end{tabular}

Note: $H \mathrm{~d}$ is dominant height, $\mathrm{m} ; A$ is $\mathrm{Age}$, year; $\mathrm{R}^{2}$ is determination coefficient; $\mathrm{S}_{\mathrm{y} . \mathrm{x}}$ is the residual standard deviation; IF is Furnival Index; F is Fischer coefficient.

The FARRAR model (the first model in Table 7) was used to assess the evolution of the dominant height as a function of age $[12,13]$. It has a higher coefficient of determination $\left(\mathrm{R}^{2}\right)$, the smallest Furnival Index (FI), and the largest Fischer coefficient (F). Besides, the test of significance of the regression coefficients shows that the latter is different from zero at the significance level. It is presented by formula (26).

$$
H d=17.46 \exp \left(\frac{-14.39}{A}+\frac{10.54}{A}\right)
$$

where: $H d$ is dominant height, $\mathrm{m}$; and $A$ is age, year.

\subsection{Growth study of Aleppo pine trees.}

Table 8 shows the dendrometric characteristics of Aleppo pine reforestation in the studied watershed of Oued Laou.

Table 8. Dendrometric characteristics of Aleppo pine reforestation.

\begin{tabular}{|c|c|c|c|c|}
\hline \multirow{3}{*}{ Characteristics } & \multicolumn{4}{|c|}{ Characteristics of Aleppo pine reforestation } \\
\hline & \multirow{2}{*}{ Average } & \multirow{2}{*}{$\begin{array}{l}\text { Standard deviation } \\
\text { of the average }\end{array}$} & \multicolumn{2}{|c|}{ Values } \\
\hline & & & $\max$ & $\min$ \\
\hline Age, year & 35 & - & - & - \\
\hline$N, \mathrm{ha}^{-1}$ & 588.54 & 121.79 & 800.00 & 366.67 \\
\hline$C \mathrm{~g}, \mathrm{~cm}$ & 92.75 & 12.81 & 118.74 & 73.75 \\
\hline$G, \mathrm{~m}^{2} / \mathrm{ha}$ & 38.87 & 4.48 & 48.20 & 32.84 \\
\hline$H \mathrm{~g}, \mathrm{~m}$ & 12.38 & 1.64 & 14.80 & 9.40 \\
\hline$H \mathrm{~d}, \mathrm{~m}$ & 13.26 & 1.56 & 15.80 & 10.60 \\
\hline$V, \mathrm{~m}^{3} / \mathrm{ha}$ & 145.25 & 19.36 & 183.60 & 117.73 \\
\hline $\mathrm{Zv}, \mathrm{m}^{3} / \mathrm{ha} /$ year & 3.82 & 0.51 & 4.83 & 3.10 \\
\hline $\mathrm{Zh}, \mathrm{cm} /$ year & 35.37 & 4.69 & 42.29 & 26.86 \\
\hline Zc, cm/year & 2.44 & 0.34 & 3.12 & 1.94 \\
\hline $\mathrm{Vb}, \%$ & 18.65 & 3.97 & 7.43 & 28.76 \\
\hline
\end{tabular}

Note: $N$ is trees number, ha ${ }^{-1} ; C \mathrm{~g}$ is circumference average, $\mathrm{cm} ; G$ is surface area per hectare, $\mathrm{m}^{2} / \mathrm{ha} ; H \mathrm{~g}$ is average height, $\mathrm{m} ; H \mathrm{~d}$ is dominant height, $\mathrm{m} ; V$ is volume, $\mathrm{m}^{3} / \mathrm{ha} ; \mathrm{Zv}$ is annual average growth in volume, $\mathrm{m}^{3} / \mathrm{ha} / \mathrm{year} ; \mathrm{Zh}$ is the annual average increment in height, $\mathrm{cm} /$ year; $Z \mathrm{c}$ is the annual average increment in circumference, $\mathrm{cm} / \mathrm{year}$; $\mathrm{Vb}$ is share of bark volume, $\%$.

\subsection{Establishment of growth models.}

3.5.1. Mean annual volume increment.

The mean annual volume increment was calculated at the level of each plot. The results show that it varies only slightly from plot to plot, which largely reflects the homogeneity of this station. The mean annual volume increment ranged from 3.10 to $4.83 \mathrm{~m}^{3} / \mathrm{ha} / \mathrm{year}$. 
Morocco's National Reforestation Plan had set a minimum productivity threshold of $4 \mathrm{~m}^{3} / \mathrm{ha} /$ year for softwood plantations. This is not quite the case for our reforestation study. However, the values of the mean annual volume increment calculated in the study area could have been better if silvicultural treatments had been properly applied to these plantations.

As an illustration, Table 9 shows some results obtained in other regions of Morocco.

Table 9. The mean annual volume increment of Aleppo pine in natural and artificial stands.

\begin{tabular}{l|l|l|l} 
Stands & Regions & $\mathbf{Z v}, \mathbf{m}^{\mathbf{3}} / \mathbf{h a} / \mathbf{y e a r}$ & Sources \\
\hline Artificial & Tensift (Morocco) & 0.75 to 2.96 & Azeba (1981) \\
& Zerhoun (Morocco) & 3.39 to 4.46 & Ankouz (1981) \\
& Tetouan (Morocco) & 0.52 to 2.79 & Laboudi (1992) \\
& Rommani (Morocco) & 1.20 to 3.71 & Ezzahiri (1982) \\
\hline Natural & Tamga (Morocco) & 0.789 to 1.406 & Belghazi (1983) \\
& Tunisia & 0.30 to 0.86 & Boudy (1950) \\
& Alegria & 1.2 to 1.5 & Boudy (1950) \\
& France & 1.5 to 5 & Parde (1957)
\end{tabular}

These results show that the mean annual volume increment of Aleppo pine in reforestation is greater than that obtained in natural stands. According to Belghazi [9], this can only be due to the right choice of prolific provenances of the seedlings raised in nurseries and the mastery of generally intensive cultivation techniques.

\subsubsection{Height increase of Aleppo pine.}

The calculation of these height increments is obtained from measurements taken on a batch of sample trees at each plot: one larger, one medium, and one smaller. The results of these calculations in our study show that the annual height increment is on average $35.37 \mathrm{~cm} /$ year. The value of the coefficient of variation is $13 \%$, which indicates that the trees grow almost equally throughout the perimeter.

\subsubsection{Aleppo pine circumference increase.}

The mean annual circumference growth study is determined based on data drawn from the average basal area tree. The average annual circumferential growth of Aleppo pine is on average $2.44 \mathrm{~cm} /$ year, with a variation coefficient of $14 \%$.

This value is of paramount importance for the professional planner who wants to stop the age of technical (mine timber) or economic (lumber) exploitability.

\section{Conclusions}

In this study, we developed specifics cubage tariffs for Aleppo pine plantations located in the Oued Laou watershed in the North of Morocco. A sample of 32 plots was adopted to cover the plantation, covering an area of 104 ha. The obtained results show that the distribution of Aleppo pine circumference is not normal. The distribution was adjusted to a normal one using the chi-squared test.

To evaluate the Aleppo pine wood production, single-entry and two-entry tariffs were constructed and then validated by calculating the relative average of cubing errors and their standard deviations. The obtained results show that the two-entry cubage tariff is more accurate than the single-entry one. Therefore, the relative average of cubing errors for the single-entry tariff is $1.16 \%$, while for the other one, it is $0.4 \%$. So, the use of either of these two tariffs depends on the degree of precision desired by the forest manager. 
A stand volume tariff was established, retracing the evolution of dominant height function to the Aleppo pine age. This tariff has the advantage of quickly estimating growing stock.

The result of the growth study of Aleppo pine shows that the mean annual volume increment is between 3.10 and $4.83 \mathrm{~m} 3 /$ ha/year from plot to plot. This slight fluctuation largely reflects the homogeneity of the study area. Morocco's National Reforestation Plan had set a minimum productivity threshold of $4 \mathrm{~m}^{3} /$ ha/year for softwood plantations. This is not quite the case for our reforestation study. However, the values of the mean annual volume increment calculated in the study area could have been better if silvicultural treatments had been properly applied to these plantations. Comparing this result to previous studies show that the mean annual volume increment of Aleppo pine in Oued Laou Watershed is greater than those obtained in natural stands, which are between 0.789 and 1.406 in the Tamga Region of Morocco [9].

The Aleppo pine height increment calculation shows that the annual height increment is on average $35.37 \mathrm{~cm} /$ year. The value of the coefficient of variation is $13 \%$, which indicates that the trees grow almost equally throughout the perimeter.

The mean annual circumference growth is on average $2.44 \mathrm{~cm} /$ year with a variation coefficient of $14 \%$. This value is of paramount importance for the professional planner who wants to stop the age of technical (mine timber) or economic (lumber) exploitability.

\section{Funding}

This research received no external funding.

\section{Acknowledgments}

This research has no acknowledgment.

\section{Conflicts of Interest}

The authors declare no conflict of interest.

\section{References}

1. Assali, F.; De Castera, H.D. Integrated forest management in Morocco (New national strategy and action plan 2019-2028), pilot study between FAO and Morocco. BioBrasil 2019, 1, 43-47.

2. El Maadidi, T.; El Aboudi, A.; Dallahi, Y.; Sahel, Y.; Boujraf, A.; Silviculture Of Aleppo Pine In The Mediterranean Region (A Case Study From Morocco). Plant Cell Biotechnology and Molecular Biology2021, 22, 57-64.

3. Belghazi, B.; Ezzahiri, M.; Romane, F. Productivity of natural stands of Aleppo pine (Pinus halepensis Miller) in the Tamga forest (High Atlas, Morocco). Cahiers Agricultures 2000, 9, 39-46.

4. Alaoui, A.; Laaribya, S.; Gmira, N. Production, growth and silvicultural management models of the main species (maritime pine and Aleppo pine) for reforestation in Morocco. Journal of Forestry Faculty2011, 11, 68-84.

5. Hajib, S.; Sbay, H.; Aafi, A.; Saidi, M. FAO in the context of the preparatory process for the State of National Forest Genetic Resources.National Report of Morocco2013, 12-17.

6. Sghaier, T.; Goubi, M.; Bentouati, A.; Kherchouche, T. Tariffs and cubing tables of individual trees of the Aleppo pine.Pinus halepensis Mill., In the Algerian Aurès. Tropical Woods and Forests2019, 339, 4559,https://doi.org/10.19182/bft2019.339.a31715.

7. I.J, Good. Further comments concerning the lady tasting tea or beer: p-values and restricted randomization. Journal of Statistical Computation and Simulation1992,263-267. https://doi.org/10.1080/00949659008811277. 
8. Löwe, R.; Sedmíková, M.; Natov, P.; Jankovský, M.; Hejcmanová, P.; Dvořák, J. Differences in Timber Volume Estimates Using Various Algorithms Available in the Control and Information Systems of Harvesters. Forests 2019, 10,https://doi.org/10.3390/f10050388.

9. Sedmíková, M.; Löwe, R.; Jankovský, M.; Natov, P.; Linda, R.; Dvořák, J. Estimation of Over- and UnderBark Volume of Scots Pine Timber Produced by Harvesters. Forests 2020, 11,https://doi.org/10.3390/f11060626.

10. Soman, H.; Kizha, A.R.; Muñoz Delgado, B.; Kenefic, L.S.; Kanoti, K. Production economics: comparing hybrid tree-length with whole-tree harvesting methods. Forestry: An International Journal of Forest Research 2020, 93, 389-400, https://doi.org/10.1093/forestry/cpz065.

11. Muñoz Delgado, B.L.; Kenefic, L.S.; Weiskittel, A.R.; Fernandez, I.J.; Benjamin, J.G.; Dibble, A.C. Northern mixedwood composition and productivity 50 years after whole-tree and stem-only harvesting with and without post-harvest prescribed burning. Forest Ecology and Management 2019, 441, 155-166, https://doi.org/10.1016/j.foreco.2019.03.032.

12. Drum, C.G.; Vogel, J.G.; Gezan, S.A.; Jokela, E.J. Belowground processes for two loblolly pine (Pinus taeda L.) families respond differently to the intensity of plantation management. Forest Ecology and Management 2019, 441, 293-301, https://doi.org/10.1016/j.foreco.2019.03.041.

13. Silamikele, I.; Jansone, B.; Sisenis, L.; Pilvere, I.; Jansons, A. Impact Of Thinning Regime On Financial Value Of Silver Birch Stand In Hemiboreal Forests: Policy Considerations. International Multidisciplinary Scientific GeoConference: SGEM 2019, 19, 731738,https://doi.org/10.5593/SGEM2019\%2F3.2\%2FS14.094. 